\title{
Denial of true-false statements and verbal ability
}

\author{
M. MICHAEL AKIYAMA, RICHARD POLLACK, MICHELLE KELLEY, and KATHY COGGINS \\ University of Oklahoma, Norman, Oklahoma
}

\begin{abstract}
Sixteen high-verbal and 16 low-verbal university students were asked to deny ordinarily true statements (e.g., $A$ ship is large), partially false statements (e.g., $A$ dog is large), and utterly false statements (e.g., $A$ fly is large). High-verbal students used affirmative statements $57 \%$ of the time to ordinarily true statements, $69 \%$ of the time to partially false statements, and $87 \%$ of the time to utterly false statements. Low-verbal students did not distinguish the three types of statements. The findings were discussed in terms of the role of verbal ability and stylistics in the English language.
\end{abstract}

People deny a statement when they find the statement utterly false or when they find the statement true but do not want to approve it. There are two basic ways in denying a statement such as $A$ ship is small. One form is to use the affirmative statement $A$ ship is large. The other form is to use the negative statement $A$ ship isn't small. Affirmative statements and negative statements can be contrasted in terms of the amount of information that each statement conveys. Affirmative statements convey more information than negative statements. For example, the affirmative statement $A$ ship is large clearly indicates that the size of a ship is at the higher end of the subjective scale of largeness. The negative statement $A$ ship isn't large, in contrast, indicates all sizes except the higher end of the subjective scale of largeness.

The affirmative-negative contrast in terms of informativeness can be used to predict how people deny utterly false statements, partially false statements, and ordinarily true statements. An utterly false statement, such as $A$ ship is small, implies ignorance about ships. A speaker denying an utterly false statement tends to use an affirmative statement with the intent of giving more information to correct the partner's ignorance (Givon, 1978).

To deny an ordinarily true statement is a form of lie. When a speaker is asked to deny a true statement, the speaker should produce a least-informative statement to avoid a totally false statement. For example, a speaker denying the statement $A$ ship is large would respond $A$ ship isn't large. In other words, the speaker uses negative statements to deny ordinarily true statements.

To deny a partially false statement falls between the above two cases. A partially false statement can be true for some speakers or for a particular instance under a

The study reported in this paper was supported in part by the University of Oklahoma Associates Funds (1983) and by the University Research Council of the University of Oklahoma. The authors would like to thank Frank Durso and Richard Reardon for their helpful reading of an earlier version of this manuscript. Requests for reprints should be sent to M. Michael Akiyama, Developmental Program, 3433 Mason Hall, University of Michigan, Ann Arbor, MI 48109. given category in the statement. For example, $A$ dog is large may be true for those who own St. Bernards but false for those who own Chihuahuas. A speaker denying a partially false statement would use both an affirmative and negative statement depending upon the speaker's judgment of the truthfulness of the statement.

In summary of the predictions, people use affirmative statements to deny utterly false statements, negative statements to deny ordinarily true statements, and both affirmative and negative statements to deny partially true statements. This paper examines whether high-verbal and low-verbal university students make differential use of affirmative and negative sentences for denial. High-verbal students might deny statements in a more differential manner than low-verbal students. In this case, the interaction of group $\times$ truth value (ordinarily true, partially false, and utterly false) should be significant.

\section{METHOD}

\section{Subjects}

Sixteen high-verbal and 16 low-verbal students were selected from 500 students enrolled in two introductory psychology classes. All subjects were given a 40 -item vocabulary test. The top 16 subjects who scored 36 or more were selected as the high-verbal group. Those 16 subjects who scored 23,24 , or 25 were selected as the low-verbal group. The low-verbal group ranked around the 10th percentile in the sample. All were native speakers of English.

\section{Task Material}

The task required the subject to say the opposite to 60 statements. Two sets of 60 statements were constructed in the following manner. First, 10 adjective antonym pairs were selected (E. Clark, 1972). These pairs were strong-weak, hard-soft, heavy-light, good-bad, fast-slow, hotcold, long-short, big-small, tall-short, and fat-skinny. Second, a positive member of the adjective pair generated 6 statements. The first 2 of them were associated with subject terms that would produce ordinarily true statements, the next 2 were associated with subject terms that would produce partially false statements, and the last 2 were associated with subject terms that would produce utterly false statements. For example, the adjective strong generated the following 2 ordinarily true statements, 2 partially false statements, and 2 utterly false statements, respectively: Superman is strong and Hulk is strong; A sheep is strong and $A$ deer is strong; $A n$ ant is strong and $A$ kitten is strong. The 2 statements from the same type were considered to be equivalent and were assigned to Set 1 or Set 2 . A negative member of the adjective pair generated 6 statements in the same manner. For example, the 6 
statements associated with weak were: An ant is weak and $A$ kitten is weak; $A$ sheep is weak and $A$ deer is weak; Superman is weak and Hulk is weak. The 2 statements from the same type were considered to be equivalent and were assigned to Set 1 or Set 2 in such a way that no identical subject terms appeared in the same set. Thus, one adjective pair generated 6 statements for Set 1 and 6 statements for Set 2 . The 120 statements constituting Set 1 and Set 2 were constructed with the additional 9 adjective pairs. Set 1 was given to half the subjects, and Set 2 to the other half.

The items within a set were randomized and were printed on two sheets of paper. After each item, its two alternative forms of denial were printed. The order of the two alternative forms was randomized across items.

\section{Procedure}

The subjects received either set of the 60 statements with their denials and written instructions. In the instructions, two different example items were given. For each item, the experimenter provided examples using an affirmative statement as well as a negative statement. After providing these examples, the experimenter asked the subjects to circle the one denial response that seemed most natural to each of the 60 statements. They were asked to imagine a situation in which the subject had a conversation with a friend and heard the statements and tried to say the opposite to them. The subjects were tested in class. A vocabulary test preceded the denial task.

\section{RESULTS}

Analyses of variance were performed on the number of semantic denials for the six types of statements. The factors were verbal group (high- or low-verbal), antonym type (unmarked and marked members of antonyms), and truth value (true, partially false, and utterly false). Both the subject factor and the item factor were treated as random (H. Clark, 1973). $F_{1}$ and $F_{2}$ are used to refer to test statistics appropriate to the design, with subjects and items, respectively, as random effects. Statistical analyses resulting in $F_{1}$ and $F_{2}$ values were named subject analyses and item analyses, respectively.

The results are shown in Table 1. The high-verbal subjects clearly distinguished the three types of statements but used semantic denial much more frequently than our formulation predicted. The high-verbal subjects used affirmative statements $57 \%$ of the time to ordinarily true statements, $69 \%$ of the time to partially false statements, and $88 \%$ of the time to utterly false statements. The main effect of truth value is highly significant $\left[F_{1}(2,28)=8.49\right.$, $\left.\mathrm{p}<.01 ; \mathrm{F}_{2}(2,108)=81.57, \mathrm{p}<.01\right]$. In contrast, the low-verbal subjects failed to distinguish between the three types of statements $\left[F_{1}(2,28)=3.19, p>.05 ; F_{2}(2,108)\right.$ $=5.16, \mathrm{p}<.01]$. Further item analyses indicate that the low-verbal students failed to distinguish between ordinarily true statements and partially false statements $\left[F_{2}(1,72)\right.$ $=2.66, \mathrm{p}>.10 \mathrm{~J}$ and between partially false statements and utterly false statements $\left[F_{2}(1,72)=3.04, p>.10\right]$.

\section{DISCUSSION}

The major finding of this experiment can be summarized as follows: High-verbal but not low-verbal university students can make differential use of affirmative and negative statements in denying ordinarily true statements, partially false statements, and utterly false statements. Given the fact that most students entering the University of Oklahoma have graduated in the top half of their high school classes, the finding implies that fewer than half of them can make use of affirmative and negative statements when denying someone's statement. There is no doubt that all native speakers of English can distinguish the semantics of ordinarily true statements (e.g., Superman is strong) from that of utterly false statements (e.g., A kitten is strong). But the problem lies in the assignment of affirmative and negative statements in denying those statements. As we discussed earlier, the assignment is based upon the judgment of the amount of information that affirmative and negative statements convey. This judgment seems to be hard to reach by low-verbal students.

The difficulty for low-verbal students in assigning affirmative-negative statements may be compared with their difficulty of verifying negative statements. Increased difficulty in verifying negative statements over affirmative statements is greater for low-verbal students than for highverbal students (Hunt, 1978). Low-verbal students seem to have general difficulty in processing negatives either in production in the present denial task or in comprehension in a verification task.

Low-verbal students' difficulty in the appropriate assignment of affirmative and negative statements may also be compared with the difficulty that verbally competent people experience under stress. People under stress tend to use negative sentences far more often than they do under normal circumstances. For example, Barry Switzer, the head football coach at the University of Oklahoma, who had been arrested for drunken driving, used nine negatives out of 16 sentences quoted by the Associated Press ("Switzer's learned his lesson?", 1984). More frequent usage of negative sentences by low-verbal students may reflect their linguistic capability comparable to those under stress.

Another finding of interest is that even high-verbal students use affirmative sentences to deny ordinarily true statements. According to our formulation, they should use negative sentences to avoid totally false statements. However, high-verbal students used affirmative statements more than half of the time. This finding may be contrasted with another finding that native speakers of English used affirmative sentences more than $56 \%$ of the time and native speakers of Japanese used affirmative statements $22 \%$ of the time in a similar task (Akiyama, Biscoe, \& Shafaie, 1985). Less frequent use of negatives among English speakers may be attributed to the stylistics unique to the English language that suppress the use of negatives (Strunk \& White, 1972).

In summary, the present study has proposed that people use affirmative statements to deny utterly false statements, both affirmative and negative statements to deny partially false statements, and negative statements to deny ordinarily true statements. Findings from high-verbal students statistically support our proposal. However, they use affirmative statements far more frequently than the proposal suggests. Findings from

Table 1

The Mean Number of Affirmative Sentences in Denying Ordinarily True Statements, Partially False Statements, and Utterly False Statements

\begin{tabular}{|c|c|c|c|c|c|c|}
\hline \multirow[b]{3}{*}{ Language Group } & \multicolumn{6}{|c|}{ Types of Statements } \\
\hline & \multicolumn{2}{|c|}{ Ordinarily True } & \multicolumn{2}{|c|}{ Partially False } & \multicolumn{2}{|c|}{ Utterly False } \\
\hline & Unmarked & Marked & Unmarked & Marked & Unmarked & Marked \\
\hline High Verbal & 5.81 & 5.56 & 6.75 & 7.13 & 9.00 & 8.56 \\
\hline Low Verbal & 5.38 & 5.00 & 5.44 & 5.88 & 6.00 & 6.31 \\
\hline
\end{tabular}

Note-The maximum number is 10.00 
low-verbal students do not support the proposal. Low-verbal students use affirmative and negative statements with equal frequency and consequently use negative statements far more often than high-verbal students.

\section{REFERENCES}

AKIYAMA, M. M. (in press). Denials in young children from a crosslinguistic perspective. Child Development.

Akiyama, M. M., Biscoe, B., \& Shafaie, S. (1985). Cross-linguistic study of denial. Manuscript submitted for publication.

Clark, E. V. (1972). On the child's acquisition of antonyms in two semantic fields. Journal of Verbal Learning and Verbal Behavior, 11, 750-758.

Clark, H. H. (1973). The language-as-fixed-effect fallacy: A critique of language statistics in psychological research. Journal of Verbal Learning and Verbal Behavior, 12, 335-359.

Givon, T. (1978). Negation in language: Pragmatics, function, ontology. In P. Cole (Ed.), Syntax and semantics: Vol. 9. Pragmatics. New York: Academic Press.

Hunt, E. (1978). Verbal abilities. Psychological Review, 85, 109-130. Strunk, W. S., \& White, E. B. (1972). The elements of style (2nd ed.). New York: Macmillan.

SWITZER'S LEARNED HIS LESSON? (1984, July 15). The Oklahoma Daily. (Manuscript received for publication September 24, 1984.) 